Noble ${ }^{1}$ in 1,118 collected cases found carcinoma of the body in 29 (2.4 per cent.), epithelioma of the cervix uteri in 12 ( 1 per cent.), sarcoma in 22 (1.8 per cent.), chorionepithelioma in 2 ( 0.16 per cent.). Another American writer who has very recently discussed this subject, Ellice MacDonald, found in 700 cases of fibromyomata malignant disease present in 35 ( 5 per cent.)-namely, adeno-carcinoma in 20 (2.9 per cent.), sarcoma in 7 $<1$ per cent.), carcinoma in 6 ( 0.5 per cent.), chorionepithelioma in 2 ( 0.29 per cent.). Kelly and Cullen ${ }^{2}$ state that " in an examination of over 1,400 cases of myomatous uteri adeno-carcinoma was detected in the body of the uterus in about 1.7 per cent." Haultain, ${ }^{3}$ in a series of 120 cases, found malignant disease in 5.8 per cent.; adenocarcinoma in 5, and sarcoma in 2. Scharlieb, ${ }^{4}$ in a series of 100 cases, found 3 cases of malignancy ( 1 sarcoma, 2 adeno-carcinoma). Very similar figures could be given from other writers, such as Bland-Sutton, ${ }^{5}$ but it is unnecessary to do so, as it is obvious that the number of cases of malignant invasion and degeneration is, as already stated, from 3 to 5 per cent.

An interesting fact in connexion with these cases of malignant degeneration is the relative frequency of the occurrence in the later decades. Although occasionally one comes across cases of malignant degeneration at an early age, as a rule at least the fiftieth year has been reached before malignancy shows itself. This is strikingly seen in the 700 cases analysed by Ellice MacDonald-5 per cent. in the fifth decade, 1.7 per cent. in the sixth decade, and 23.7 per cent. in the seventh decade.

With such experiences it is not surprising that gynaecologists are becoming more and more afraid to leave f́bromyomata alone, and some are even going the length of saying that they should always be operated upon whenever recognized. The majority of us, however, in view of the fact that many fibromyomata give rise to no trouble and cause no interference with the course of pregnancy and parturition, are still disposed to tэmporize in many cases. The question, then, we have to face is When is it dangerous to temporize? We are all agreed that haemorrhage and pressure symptoms indicate imme diate interference, but what we wish to try to arrive at is the indications which render interference necessary, eren if these ordinarily recognized disturbances are not present. We wish to try to recognize the cases in which malignant degeneration or invasion has begun.

In a considerable number of cases we may suspect, and in many recognize, the malignancy. In cases of adenocarcinoma-and this is the most common variety of malignancy-curettage of the uterus and an examination of the scrapings will give us the information. But sometimes the uterine cavity is most difficult to explore by reason of its distortion by the tumours; and in cases of sarcoma curettage is generally of no value, as the malignant degeneration rarely commences in the endometrium. Pain is always suspicious, and in my experience pain is much more commonly a symptom in adeno-carcinoma which has invaded fibroids than in adeno-carcinoma attacking an - otherwise normal aterus. An increase of haemorrhage is also very general, and not infrequently there is a distinct increase in the swelling.

Lastly, there is the important fact that in a very large proportion of cases malignant invasion and degeneration do not occur until after the fortieth year, when the uterus is of little physiological value, and when one naturally has very little compunction in removing it. By the history, the age of the patient, and curettage, we will be able, I think, in most cases to recognize malignant changes, and can therefore safely allow a certain number of fibromyomata to remain unoperated upon. But the cases we should certainly never leave alone are those that continue to be associated with any disturbances, and, above all, with any haemorrhage after the fortieth year.

The operation of hysterectomy for fibroid tumours of the aterus has become one of such comparative safety that we can safely reckon on a death rate of not more than 2 per cent.

\section{THE TREATMENT OF}

\section{CHRONIC OÖPHORITIS AND ASSOCIATHD CONDITIONS.}

By T. CAMERON, M.B., C.M.GLasG.,

SURGEON, THE HOSPITAL FOR WOMEN, AND ASSISTANT SURGEO VICTORIA HOSPITAL FOR SICK CHILDREN, HOLL.

THE following is reported because a large number of such cases are met with in gynaecological practice and are difficult to deal with so as to give satisfactory after-results. The more conservative treatment which is now adopted, when in the course of an operation inflamed, adherent, prolapsed, and cystic ovaries have to be dealt with (or various combinations of these conditions), does not always meet with unqualified success. The removal of diseased elements in the ovary and the conservation of whatever part that may be deemed sufficiently healthy to retain, is good practice as far as it goes. Associated with adhesions which have to be divided or torn through, and a prolapsed condition of the ovary, we meet with conditions which require something more than the ordinary measures mentioned in textbooks, in order that reasonable assurance of completely relieving the patient's symptoms may be obtained. When adhesions are freed we are left with raw surfaces of more or less extent, both on the surface of the ovary and the peritoneal surface of Douglas's pouch, so that there is considerable risk that fresh adhesions may form. The mesentery of the ovary is often weak and stretched, so that, unless special precautions are adopted, not only may the ovary become adherent but it is apt to do so in a faulty position.

Before adopting the measures to be described later, I have usually stitched the ovary to the broad ligament or shortened the mesentery, with or without simultaneously performing a suspension of the uterus. This gave variable results-some good, others not. In estimating results, most importance has been attached to the presence or absence of pain. These cases always apply on account of pain in one form or another. It may be almost constant in character, and aggravated on the least exertion; usually there is dispareunia and severe dysmenorrhoea. Occasicnally defaecation aggravates the pain considerably.

No doubt there are cases of old-standing inflammation and adhesions of the ovaries in which there is little or no pain, but these do not come up for operation. The question-what is the main element in producing pain in these cases?-is interesting. It may be the direct effect of the inflammatory condition, just as in any other organ. In displaced ovaries the venous return seems to be interfered with, and the veins are often varicose. Sometimes the pain appears to be "neuralgic."

The nature of the numerous small cysts met with in many cases is also of interest. Olshausen suggests that they are true retention cysts - that is, due to sclerosis of the periphery of the ovary, which prevents the Graafian follicles from discharging their contents at the surface. Judging, however, from the large number of cysts sometimes found, their equality in size and often their distribution throughout the ovary, it appears to be more probable that there is an inflammatory action in the Graafian follicles which induces a condition of hydrops. I only mention the matter here because there is a probability that the pressure of these cysts may be another factor in producing pain in the ovary.

For practical purposes it may be assumed that each cause plays some part in the causation of pain.

In the course of an operation, when all adhesions have been dealt with and cysts dissected out of the ovaries, or a section of an ovary more markedly affected by cystic formation removed, the next step is to restore the ovary as much as possible, by stitching with fine catgut, so as to bring all raw surfaces into apposition, and renew as much as possible the general shape and contour of the organ.

In operating upon these cases, and in cases also in which there is a more acute degree of infection, such as cases of pyosalpinx, ovarian abscess, and so on, I have been struck by the wonderful immunity enjoyed by the anterior surface of the broad ligament as compared with the posterior. Whilst adhesions, the deposition of lymph, and all the other signs of an infective peritonitis are found 
posteriorly, the Fallopian tubes seem to form a boundary, in front of which is a region almost immune from the invasion of infective organisms and the sequela which follow them. Taking advantage of this observation I have devised an operation which, so far as a limited experience goes, seems to solve the problem.

The broad ligament is pat upon the stretch by pulling the Fallopian tube upwards, and the ovary is pulled away at right angles to it, so as to get an idea of the length of the ovarian mesentery. A pair of sharp-pointed scissors is now thrust through the broad ligament from behind forwards at a point corresponding to the junction of the middle with the outer third of the ligament, and 1 in. below the level of the lower margin of the Fallopian tube. The opening is then enlarged sufficiently to allow of the delivary of the ovary through it on to the anterior surface of the broad ligament. The ovarian pedicle is now attached to the borders of the incision in the broad ligament on its anterior aspect by two catgut retaining stitches, one on each side. By this means the ovary is secnrely fixed in ios new position. The opening in the broad ligament is reduced in size by approximating the edges with catgut. It is thought important, however, not to constrict the ovarian pedicle unduly. Any raw surfaces on the posterior aspect of the broad ligaments are invaginated and stitched over as far as possible, so as to present a smooth peritoneal surface.

The following case is typical of those which have been operated upon according to the method just described.

The symptoms were pain and tenderness over both iliac regions, and pain in the sacral region. There was dysmenorrhoea of a severe character and dyspareunia. On examination the ovaries were found to be enlarged, prolapsed into Donglag' pouch, and adherent. Pressure upon these by the examining finger caused exquisite pain.

An operation was carried ont substantially as described above The ovaries were freed from dense adhesions, a well-marked The ovaries were freed from dense adhesions, a well-marked cystic condition dealt with, and the operation otherwise com-
pleted as indicated above. During the five months which have plapsed since the operation, pain has been absent, and in every other respect the patient has enjoyed very good health.

An objection which could be urged against this operation is the possible effect of pregnancy upon the pedicle of the ovary. As the gravid uterus gradually expands, the ovarian pedicle might be injuriously affected. It was considered that any such risk would be obviated by making the incision in the ligament as far externally as the length of the ovarian pedicle will permit. In the first place, even in a uterus at full time, one finds, in cases of Caesarean section, for instance, that there is a quite definite amount of broad ligament left. In the second place, the gradual stretching which takes place would obviate any risk of strangulation or other injury to the pedicle,

The new position of the ovary facilitates the emptying of its veins, and to this is to be attributed in part the successful results obtained. If there be an associated condition of malposition of the uterus, such as retroflexion or prolapse, this, it will be understood, should be dealt with before finally closing the abdominal wound.

DR. LUDWIG MOND, who during his lifetime made many gifts to scientific institutions in this country, including in particular his foundation of the Davy-Faraday Laboratory in connexion with the Royal Institution, has bequeathed a sum of $£ 50,000$ free of duty to the Royal Society of London. The income derived from this bequest is to be employed in the endowment of research in natural science, more par. ticularly, but not exclusively, in chemistry and physics, by providing awards for new discoveries and by giving pecuniary assistance, including scholarships, by supply. ing apparatus and appliances for laboratories and observatories, and by improving existing or erecting new laboratories and observatories, and in such other manner as the Royal Society may decide to be best calculated to promote scientific research. The society is also authorized to spend a part of the incorne in the publication and circulation of reports and papers communicated to it and in the preparation and publication of catalogues and indexes of scientific literature. Dr. Mond also bequeathed a similar sum to the University of Heidelberg for the endowment of research in natural science. He likewise bequeathed to the nation, under certain conditions, a number of pictures from his collection of early Italian masters. The bequests are subject to the life interest of his wife.
ECTOPIC FETATION : LAPAROTOMY : DIFF USE PERITONITIS : RECOVERY.

\author{
BY \\ J. GARDINER, \\ B.A OXON, M.R.C.S.ENG.
and H. W. WEBBER, M.S.LoND., \\ SURGEON TO THE SOUTH DEVON \\ AND EAST CORNWALL HONPITAL.
}

THu following case presents several features of interest which render it worthy of notice:

The patient, aged 22, was first seen by Mr. Gardiner on October 5th, 1909, when the following history was obtained :

She was married on July 15th, 1909, and the mid-August. menstrual period was quite usual in every respect. The next period, due about September 10th, was much less than usual, and towards the end of the month haemorrhage commenced again and continued up to October 5th in varying amounts.

The os uteri was not patulous, there was slight vaginal haemorrhage, and some tenderness to the right of the uterus on bimanual examination.

morphine was prescribed.

On October 7th, the haemorrhage being rather increased, the vagina was packed with iodoform gauze in the morning. On removing the gauze on October 8 th some shreds of mucous. membrane apparently of decidual nature came away, and on bimanual examinatiou the tenderness to the right of the uterus was marked, and a small rounded soft swelling was detected. On October 9th, in the morning, she was more comfortable, but in the evening pain returned on the right side of the pelvis, and Mr. Webber saw her with Mr. Gardiner at 10.30 p.m. At this time the pulse was 85 and the temperature $99^{\circ}$ F. Vaginal examination disclosed nothing definite, the patient being in great pain, and satisfactory examination impossible.

At 11 p.m. the pulse had risen to 120 , and the patient's condition had changed considerably. She was now blanched and collapsed.

It was decided to open the abdomen as soon as possible, but by the time instruments, dressings, nurse, and anaesthetist by the time instruments, dressings, nurse, and anaesthetist were obtained, and a table, etc., prepared, it was past midnight. the patient was pulseless when placed on the table, and 2 pintsof saline solution were injected intravenously before commencing laparotomy. The ruptured right tubal gestation sac-
was found at once, clamped, and removed, and ligatures applied.
as quickly as possible. All effused blood and clots were sponged. out, and the abdomen closed by mass sutures of salmon gut. By this time the radial pulse had again become imperceptible and the breathing very feeble. An attempt to infuse more saline solution failed; in neitber arm could a vein be found of size sufficient to admit the cannula. Saline was therefore given by the rectum, and 2 pints were slowly run in and retained. Under this treatment, with strychnine injections in addition, and small doses of brandy by the mouth as soon as conscious, the patient doses of rallied, and was left at 6 a.m. With a small, weak pulse of about 140. All day (October 10th) she remained on the operating table with its foot raised $2 \mathrm{ft}$; ; at 7 p.m. the pulse being 120 , tion were slowly absorbed by the rectum, and sips of hot water. tion were slowly absor

taken by the mouth. On October 1lth the patient began to suffer from hiccough,
and by the afternoon vomiting of dark greenish-brown fluid commenced; the pulse was 130 , temperature $100.6^{\circ}$, respirations 34 , and abdominal tenderness and distension present. At 5 p.m Mr. Gardiner administered A.C.E. mixture, and, two suture being removed, a rubber drainage-tube was passed into Douglas's pouch, some iodoform gauze being packed down to the right of the uterus, as a certain amount of haemorrhage came by the side of the tube. She ras now placed in the Fowler position, and inclined to the left side, and the saline again poinini administer drainage from the pelvis, cessation of the vomiting, and fall of drainage from the pelvis, cessation of the vomiting, and fall the temperature, so that on October 12 th it was 99.2 , and the pulse 120; the abdomen was distended, some hiccough present, but no vomiting, and less abdominal pain. A soap and water enema produced a good result. On October 13th the hiccough ceased, and some albumen water and weak beef-broth were
retained; \& rectal enema gave a fair result, and the patient's retained; \& rectal enema gave a fair result, and the patient's general condition was much improved. On October 14th the ganze was removed under A.C.E. \&nasthesia, the tube being
left in situ. On October 16th it was necessary to remove some stitches on account of infection of the abdominal wall, and apply boracic fomentations. The patient began to take solid food on October 17th, and daily shortening of the tube was commenced. Menstruation reappeared on October 19th.

Remarks.

The points of interest in this case are :

1. The age of the patient, and the almost immediate. supervention of the abnormal pregnancy on marriage. The gestation sac was the size of an ordinary walnut; the 